\title{
Variations of serum testosterone levels in prostate cancer patients under LH-releasing hormone therapy: an open question
}

\author{
Leonardo Oliveira Reis ${ }^{1,2}$
}

\author{
${ }^{1}$ Department of Surgery (Urology), Faculty of Medical Sciences, University of Campinas (Unicamp), Rua Tessália Vieira de \\ Camargo, 126 Cidade Universitária Zeferino Vaz, Campinas, São Paulo CEP 13083-887, Brazil \\ ${ }^{2}$ Medicine (Urology), Center for Life Sciences, Pontifical Catholic University of Campinas (PUC-Campinas), Brazil \\ (Correspondence should be addressed to L O Reis; Email: reisleo@ unicamp.br)
}

\begin{abstract}
The hypothesis 'the lower the better when achieving castration levels of testosterone' is based on the data from second-line hormonal manipulation and its molecular basis, and on better oncological results reported for lower castration levels in prostate cancer (PCa) patients, including those achieved with maximal androgen blockade. In this regard, the equivalence of surgical and different pharmacological castrations has been controversial. The modified amino acid structure that makes $\mathrm{LH}$-releasing hormone $(\mathrm{LHRH})$ analogs more potent than $\mathrm{LHRH}$, and the method of delivering the analogs impacts on bioavailibility and potentially causes differences in androgen levels and in its final oncological efficacy. In addition to this, there is a myriad of circumstances, such as those related to ethnic variations and co-morbidities, which uniquely impact on the pharmacological approach in a highly heterogeneous population of castration-resistant prostate cancer (CRPC) patients. Ineffective testosterone suppression through hormonal escape is currently poorly recognized and may result in increased PCa mortality. Until now, the optimal serum testosterone level in patients under castration, and the impact of its variations in patients under LHRH therapy, remain open questions and have been merged to a broad spectra of patients who are highly heterogeneous. This heterogeneity relates to a number of mechanisms regarding response to treatment, which influences the biology of the relapsing tumor and the sensitivity to subsequent therapies in the individual patient. The rationale to achieve testosterone levels below 20-50 ng/dl warrant further investigation as these levels have recently rescued CRPC patients. In the last few years and months, important advancements in prostate cancer treatment have been achieved. Nevertheless, these advances are measured in a few months of additional survival and under high costs, not available to most of the world population, compared with the benefits of hormonal manipulation that are measured in years, there is a huge potential for accessible and durable effect expansion and optimization of treatment, particularly with the current tendency of a more individual approach.
\end{abstract}

Endocrine-Related Cancer (2012) 19 R93-R98

\section{Introduction}

During the last 20 years, surgical castration has been replaced by the medical use of LH-releasing hormone (LHRH) agonists, as a well tolerated treatment option for prostate cancer $(\mathrm{PCa})$, and with comparable testosterone castration cutoff. A level of $50 \mathrm{ng} / \mathrm{dl}$ is obtained using old assay methods (Wilke \& Utley 1987); however, since 1996, a method using chemiluminescent technology for clinical use (Wheeler et al. 1996) resulted in more accurate serum testosterone measurements, and currently the sensitivity of this assay has an accuracy level close to $0.1 \mathrm{ng} / \mathrm{dl}$ (Zherdev et al. 2003).

In this scenario, the equivalence of surgical and different pharmacological castrations has been contested, and it is of concern that most of the phase III studies for the Food and Drug Administration licensing of LHRH agonists were based on the previous $50 \mathrm{ng} / \mathrm{dl}$ castration level defined by the historical assay limitation (Wilke \& Utley 1987, Sharifi et al. 1996). 
Adding to this controversy is a cluster of evidence supporting the hypothesis 'the lower the better when achieving castration levels of testosterone', based on the data from second-line hormonal manipulation and its molecular basis (Reis 2011), and on better oncological results (survival free of castration-resistant prostate cancer (CRPC)) reported for patients with castration levels $<32 \mathrm{ng} / \mathrm{dl}$ (Morote et al. 2007).

Although an imperative clinical consideration, ineffective testosterone suppression (ITS) through hormonal escape is not recognized when serum testosterone is not systematically monitored, culminating in very scarce data analyzing the impact of serum testosterone levels and breakthrough increases in $\mathrm{PCa}$ clinical outcome.

Levels of serum testosterone have been reported to be $>20 \mathrm{ng} / \mathrm{dl}$ in $13-35 \%$ and $>50 \mathrm{ng} / \mathrm{dl}$ in $2-13 \%$ of patients receiving LHRH agonists (Tombal 2005).

Clinical trials comparing outcomes among the various forms of hormonal therapy have reported no survival advantage for orchiectomy that achieves lower testosterone levels than the monthly LHRH agonist (i.e. $3.6 \mathrm{mg}$ goserelin acetate, $3.75 \mathrm{mg}$ leuprolide acetate, or $7.5 \mathrm{mg}$ leuprolide acetate). However, they must be interpreted cautiously once they are not powered to detect small differences in outcome, owing to a relatively short median follow-up $(<15$ months), and patients' heterogeneity (Kaisary et al. 1991, Vogelzang et al. 1995).

The fact that values up to $30 \mathrm{ng} / \mathrm{dl}$ were also observed in surgically castrated cases (Oefelein et al. 2000), and that a modest overall and cancer-specific survival has been shown on meta-analysis for maximal androgen blockade (MAB), obtained by the addition of an oral antiandrogen compared with castration alone (Schmitt et al. 2000), supports the results of clinical relevance of $32 \mathrm{ng} / \mathrm{dl}$ for an effective castration (Morote et al. 2007).

Furthermore, recent data suggest that about $70 \%$ of patients experienced decreased prostate specific antigen (PSA) after the LHRH switch, and this decrease appeared more pronounced when switching from leuprolide to goserelin rather than vice versa (Lawrentschuk et al. 2011). These data suggest that the pharmacodynamics of these agents may be different.

Although CRPC is a more precise and recommended definition compared with androgen independently (Reis 2011), it aggregates a highly heterogeneous population, considering that some trials have shown that individual LHRH analogs can act differently and at their respective doses induce castration over differing time frames and to different levels (Heyns et al. 2003).
The degree of potency of LHRH analog peptides varies according to their modified amino acid structures, and thus the effect on the pituitary-gonadal axis may vary with the agent. Also, the method of delivery has an impact on bioavailability and potentially causes differences in androgen levels (Chodak 1989).

In this scenario, ITS may result in increased PCa mortality, and until there is better understanding of LHRH therapy, periodic testosterone monitoring ensures appropriate androgen deprivation. Future studies are warranted to label and classify LHRH agonists from a regulatory perspective in different classes according to their efficacy now there is rapidly growing evidence that the depth of the testosterone nadir is associated with a survival advantage in men with metastatic PCa (Morote et al. 2007, Perachino \& Cavalli 2008, Perachino et al. 2010).

In general, maximal Leydig cell suppression is achieved within the first month after initiation of the 1- or 3-monthly depot preparations of LHRH analogs. An open-label study designed for regulatory authorities to evaluate leuprolide acetate $(3.75 \mathrm{mg})$ depot formulation for commercialization has shown that by day 28 , $96.8 \%(151 / 156)$ and $73.1 \%(114 / 156)$ of evaluable patients had testosterone concentrations $\leq 50$ and $\leq 20 \mathrm{ng} / \mathrm{dl}$ respectively (Marberger et al. 2010).

Previous reports on failure to achieve castration have involved leuprolide acetate. Analyses have indicated that inter-patient variance is greater for patients receiving leuprolide (Smith \& McGovern 2001, Yri et al. 2006).

A cross-sectional, retrospective, non-randomized study showed that 4 out of 65 patients treated with LHRH analog did not have a serum testosterone level within the female range $(2.8 \mathrm{nmol} / \mathrm{l}, 81 \mathrm{ng} / \mathrm{dl})$ during treatment with leuprolide acetate but were within the range with goserelin acetate. This suggests that the LHRH equivalence is valid at the group level, but may not be true for individual patients (Yri et al. 2006).

Another study, randomizing 22 patients to receive either goserelin $3.6 \mathrm{mg}(n=11)$ or leuprolide $3.75 \mathrm{mg}$ $(n=11)$, found that after 28 days, total testosterone decreased to within a range observed following castration $(<50.0 \mathrm{ng} / \mathrm{dl})$ in all patients except for one in the leuprolide group. However, the mean rate of decrease in LH concentration was significantly greater in the goserelin group compared with the leuprolide group, and at day 21, compared with goserelin, leuprolide was associated with a significantly smaller dispersion in the rate of decrease in PSA, and the dispersion of the rate of change in total testosterone 
concentration was significantly greater with leuprolide than with goserelin at day $21 \quad(P=0.0235$; folded $F$ test). Furthermore, although the magnitude of the initial LH surge and low incidence of tumor-flare reactions were similar in both groups, leuprolide appears to be associated with a greater initial testosterone surge than goserelin (Tanaka et al. 2007).

Although the clinical significance of this difference in testosterone is uncertain, goserelin is the only LHRH agonist shown to improve overall survival when used as an adjuvant to radiotherapy in locally advanced disease (Bolla et al. 2002, Pilepich et al. 2005) and to radical prostatectomy in patients with node-positive disease (Messing et al. 1999).

From 73 consecutive patients with PCa, treated with 3-monthly depot LHRH agonists, the rate of breakthrough increases in serum testosterone over any castrate level over time was considerable. Irrespective of the LHRH agonist, the probability of a future breakthrough increase could be predicted, and three determinations of $<20 \mathrm{ng} / \mathrm{dl}$ should guarantee no future breakthrough increases of $>50 \mathrm{ng} / \mathrm{dl}$ (Morote et al. 2009).

A meta-analysis including 12 trials, comparing LHRH agonist monotherapy with orchiectomy or diethylstilbestrol, suggested that they are essentially equivalent to orchiectomy in terms of survival; however, none of these trials directly compared the LHRH agonists (Seidenfeld et al. 2000) and the power of the study might be regarded as insufficient to detect very small survival differences.

The reason for insufficient androgen deprivation during LHRH treatment is not understood, and there is speculation over whether obesity interferes in the pharmacokinetics of the drugs used to alter the LHRH receptor, antibodies against the drug, blocked absorption, or its rapid metabolization.

It was shown that despite lower pretreatment serum testosterone levels, obese men (body mass index (BMI) $>30 \mathrm{~kg} / \mathrm{m}^{2}$ ) had total and free testosterone levels 1.8 and 2.3 times greater, respectively, than those in normal men after 48 weeks of leuprolide 3-month (22.5 mg) depot treatment (Smith 2007).

Also, it was proposed that the effects of LHRH agonist in suppressing serum testosterone levels differ among the races. Although there were testosterone levels just outside the castrate range in a few patients during treatment, 1- and 3-monthly formulations of leuprolide and goserelin had equivalent and sufficient effects to suppress serum testosterone levels in a retrospective study including 232 Japanese men with PCa (Fujii et al. 2008).
In the 2001 version of the PCa guidelines, the National Comprehensive Cancer Network (NCCN) recommended that orchiectomy or MAB should be considered if a patient's serum testosterone level was $>20 \mathrm{ng} / \mathrm{dl}$ during GNRH agonist monotherapy, also known as LHRH agonist (National Comprehensive Cancer Network. Treatment guidelines for patients: prostate cancer. Www.nccn.org/index.asp (version II, last update 2001)). This threshold is not evidence based and this was not recommended in the subsequent versions of the NCCN guidelines while better evidence was awaited.

A modest advantage in the 5-year cancer-specific survival probabilities in favor of those patients randomized to MAB (1.8-5\%; Prostate Cancer Trialists' Collaborative Group 2000, Schmitt et al. 2000) indicates the potential impact of further hormonal manipulation in patients with testosterone levels in the range of 20-50 ng/dl as well as in those patients failing to reach the standard castration level $(<50 \mathrm{ng} / \mathrm{dl})$.

Similarly, the sequential responses to hormonal manipulation, known as secondary hormonal therapy, implies that androgen receptor (AR) signaling remains an important therapeutic target and also relies on the fact that CRPC is not necessarily androgen-independent and is susceptible to further hormonal manipulation. Abiraterone, a CYP17 inhibitor that effectively blocks the conversion of androgens from non-gonadal precursors, thus reducing testosterone to undetectable levels, has recently been proved to extend survival rates for men with metastatic CRPC who have progressive disease even after first-line chemotherapy treatment (Reis 2011).

In this context, although better evidence is necessary, the rescue of CRPC patients by using abiraterone supports the rationale of an important role for androgen depletion or androgen levels below $50 \mathrm{ng} / \mathrm{dl}$ or even below $20 \mathrm{ng} / \mathrm{dl}$ (Reis 2011). The rationale to achieve testosterone levels below $20-50 \mathrm{ng} / \mathrm{dl}$ needs to be studied further in the PCa scenario, for those classified as CRPC and even for the hormone-naive patients.

Until now, the optimal serum testosterone level in patients under castration and the impact of its variations in patients under LHRH therapy remain uncertain. In the current scenario of advancements measured in a few months and under high costs, which are not available to most of the world population, compared with the benefits of hormonal manipulation that are measured in years (Reis 2011), this denotes a huge potential for accessible and durable effect expansion and optimization of treatment, particularly for the current tendency of a more individual approach. 
Adding to this complex and challenging scenario is the fact recently confirmed by our group that the efficiency of the different available pharmacological castration solutions aimed at reaching castration levels, mainly for cutoff $\leq 20 \mathrm{ng} / \mathrm{dl}$, can vary significantly; surprisingly, about half and one-third of patients did not achieve castration levels of 20 and $50 \mathrm{ng} / \mathrm{dl}$ respectively (Silva et al. 2012).

On the other hand, the differential response to androgen withdrawal and the resulting effect on survival have motivated important studies supporting the critique concerning the hypothesis of all or none of the manner presenting a response to androgen withdrawal (Hussain et al. 2006).

We have previously highlighted (Reis 2011) that although the AR is the major therapeutic target of $\mathrm{PCa}$, there are currently no clinical studies available in which the AR status was considered in the study design. Furthermore, to date, even with better understanding of the molecular pathways behind CRPC, no study on secondary hormonal treatment with strong methodology has shown a benefit in terms of survival, but most trials have been smaller and heavily biased for patients' heterogeneity.

It is of concern that although in the last 2 years, three approved treatments based on Phase III trials have demonstrated modest survival improvements (measured in months) in CRPC (cabazitaxel (potent taxane able to bypass the main resistance mechanism to docetaxel drug efflux pump, $P$-glycoprotein 1; approved in 2010); sipuleucel-T (immunotherapeutic agent through dendritic cells; approved in 2010); and abiraterone (orally active, potent and irreversible inhibitor of CYP17 - a critical enzyme in androgen biosynthesis; approved in 2011)), palpable advancement in hormonal management has been scarce and underexplored (Reis 2011, Silva et al. 2012).

Recently, stunted attempts by more complete and occasionally intermittent androgen blockade have been described (Scholz et al. 2007); however, these strategies are clearly less appetizing to the pharmaceutical industry, the well-recognized engine of research funding in the field of clinically advanced PCa treatment.

The very first and essential steps might be to know the real level of ITS through hormonal escape, which can vary individually among patients, and its tangible rate as they are currently poorly recognized and have been merged to patients' heterogeneity. Aspects such as ethnic and co-morbidity variations are fundamental in this setting, and therefore studies around the world including different races and different patients' profiles would be beneficial.
Even through relatively methodologically unsound studies, a broad spectra of patients has been identified, involving a number of mechanisms regarding the response to treatment, and many prognosticators, including: no prior hormone exposure, responsiveness to second-line therapy, and the effects of a drug on each parameter of disease independently (Scher et al. 1997, Suzuki et al. 2008).

The specific hormone therapy administered and the response to that therapy can influence the biology of the relapsing tumor and the sensitivity to subsequent therapies, and are therefore predictors of increased survival in individual patients. In this regard, a PSA of $4 \mathrm{ng} / \mathrm{ml}$ or less after 7 months of androgen deprivation through goserelin and bicalutamide is a strong predictor of survival (Hussain et al. 2006).

There are unquestionably different molecular determinants on why one cancer would respond to possibly slightly higher levels than another, and this presumably relates to how the AR is working (Scher et al. 1997). Briefly, at least five fundamental mechanisms are AR mediated (three of which depend on ligand signaling), which contribute to the stem-cell pathway: persistence of intratumoral androgens as a result of in situ steroidogenesis or adrenal source; $A R$ mutations that allow promiscuous activation by the otherwise nonsignaling ligands; wild-type $A R$ gene amplification; alterations in the AR co-activator:corepressor ratio that impact transcription; and outlaw AR pathways that bypass the need for androgens by signaling through cross talk with other ligand-bound receptors, cytokines, or transactivation of activated tyrosine kinase receptors in the cytosol (consider reference (Reis (2011)) for a comprehensive review on the molecular basis).

Further research is required to gain greater understanding of the issues, particularly with regard to the evidence-based clinical aspects. Therefore, appropriately large cohorts of patients with the right design, precise targets, and very long follow-up periods, combined with oncological and survival primary outcomes, are necessary to avoid future studies being underpowered (Reis et al. 2010).

\section{Declaration of interest}

The author declares that there is no conflict of interest that could be perceived as prejudicing the impartiality of the review reported.

\section{Funding}

This review did not receive any specific grant from any funding agency in the public, commercial or not-for-profit sector. 


\section{References}

Bolla M, Collette L, Blank L, Warde P, Dubois JB, Mirimanoff RO, Storme G, Bernier J, Kuten A, Sternberg C et al. 2002 Long-term results with immediate androgen suppression and external irradiation in patients with locally advanced prostate cancer (an EORTC study): a phase III randomized trial. Lancet 360 103-106. (doi:10.1016/ S0140-6736(02)09408-4)

Chodak GW 1989 Luteinizing hormone-releasing hormone (LHRH) agonists for treatment of advanced prostatic carcinoma. Urology 33 42-44. (doi:10.1016/00904295(89)90105-2)

Fujii Y, Yonese J, Kawakami S, Yamamoto S, Okubo Y \& Fukui I 2008 Equivalent and sufficient effects of leuprolide acetate and goserelin acetate to suppress serum testosterone levels in patients with prostate cancer.

BJU International 101 1096-1100. (doi:10.1111/j.1464410X.2007.07374.x)

Heyns CF, Simonin MP, Grosgurin P, Schall R, Porchet HC \& South African Triptorelin Study Group 2003 Comparative efficacy of triptorelin pamoate and leuprolide acetate in men with advanced prostate cancer. BJU International 92 226-231. (doi:10.1046/j.1464410X.2003.04308.x)

Hussain M, Tangen CM, Higano C, Schelhammer PF, Faulkner J, Crawford ED, Wilding G, Akdas A, Small EJ, Donnelly B et al. 2006 Absolute prostate-specific antigen value after androgen deprivation is a strong independent predictor of survival in new metastatic prostate cancer: data from Southwest Oncology Group Trial 9346 (INT-0162). Journal of Clinical Oncology 24 3984-3990. (doi:10.1200/JCO.2006.06.4246)

Kaisary AV, Tyrrell CJ, Peeling WB \& Griffiths K 1991 Comparison of LHRH analogue (Zoladex) with orchiectomy in patients with metastatic prostatic carcinoma. British Journal of Urology 67 502-508. (doi:10.1111/ j.1464-410X.1991.tb15195.x)

Lawrentschuk N, Fernandes K, Bell D, Barkin J \& Fleshner N 2011 Efficacy of a second line luteinizing hormonereleasing hormone agonist after advanced prostate cancer biochemical recurrence. Journal of Urology 185 848-854. (doi:10.1016/j.juro.2010.10.055)

Marberger M, Kaisary AV, Shore ND, Karlin GS, Savulsky C, Mis R, Leuratti C \& Germa JR 2010 Effectiveness, pharmacokinetics, and safety of a new sustained-release leuprolide acetate 3.75 -mg depot formulation for testosterone suppression in patients with prostate cancer: a phase III, open-label, International Multicenter Study. Clinical Therapeutics 32 744-757. (doi:10.1016/ j.clinthera.2010.04.013)

Messing EM, Manola J, Sarosdy M, Wilding G, Crawford ED \& Trump D 1999 Immediate hormonal therapy compared with observation after radical prostatectomy and pelvic lymphadenectomy in men with node-positive prostate cancer. New England Journal of Medicine 341 1781-1788. (doi:10.1056/NEJM199912093412401)
Morote J, Orsola A, Planas J, Trilla E, Raventós CX, Cecchini L \& Catalán R 2007 Redefining clinically significant castration levels in patients with prostate cancer receiving continuous androgen deprivation therapy. Journal of Urology 178 1290-1295. (doi:10.1016/j.juro.2007.05.129)

Morote J, Planas J, Salvador C, Raventós CX, Catalán R \& Reventós J 2009 Individual variations of serum testosterone in patients with prostate cancer receiving androgen deprivation therapy. BJU International 103332. (doi:10.1111/j.1464-410X.2008.08062.x)

Oefelein MG, Feng A, Scolieri MJ, Ricchiutti D \& Resnick MI 2000 Reassessment of the definition of castrate levels of testosterone: implications for clinical decision making. Urology 56 1021. (doi:10.1016/S0090-4295(00)00793-7)

Perachino M \& Cavalli V 2008 Testosterone (T) level correlates with survival in pts with advanced prostate cancer (APC): the lower is really the better. Journal of Urology 179 179. (doi:10.1016/S0022-5347(08)60520-0)

Perachino M, Cavalli V \& Bravi F 2010 Testosterone levels in patients with metastatic prostate cancer treated with luteinizing hormone-releasing hormone therapy: prognostic significance? BJU International 105648. (doi:10.1111/j.1464-410X.2009.08814.x)

Pilepich MV, Winter K, Lawton CA, Krisch RE, Wolkov HB, Movsas B, Hug EB, Asbell SO \& Grignon D 2005

Androgen suppression adjuvant to definitive radiotherapy in carcinomas of the prostate - long term results of phase III RTOG 85-31. International Journal of Radiation Oncology, Biology, Physics 61 1285-1290. (doi:10.1016/j.ijrobp.2004. 08.047)

Prostate Cancer Trialists' Collaborative Group 2000 Maximum androgen blockade in advanced prostate cancer: an overview of the randomised trials. Lancet 3551491. (doi:10.1016/S0140-6736(00)02163-2)

Reis LO 2011 Old issues and new perspectives on prostate cancer hormonal therapy: the molecular substratum. Medical Oncology [in press]. (doi:10.1007/s12032-0119991-z;PMID:21626233)

Reis LO, Vieira LF, Zani EL, Denardi F, de Oliveira LC \& Ferreira U 2010 Assessment of serum chromogranin-A as prognostic factor in high-risk prostate cancer. Journal of Investigative Medicine 58 957-960. (doi:10.231/JIM. 0b013e3181f5d610)

Scher HI, Liebertz C, Kelly WK, Mazumdar M, Brett C, Schwartz L, Kolvenbag G, Shapiro L \& Schwartz M 1997 Bicalutamide for advanced prostate cancer: the natural versus treated history of disease. Journal of Clinical Oncology 15 2928-2938.

Schmitt B, Bennett C, Seidenfeld J, Samson D \& Wilt T 2000 Maximal androgen blockade for advanced prostate cancer. Cochrane Database of Systematic Reviews 2 CD001526. (doi:10.1002/14651858.CD001526)

Scholz M, Lam R, Strum S, Jennrich R, Johnson H \& Trilling T 2007 Prostate-cancer-specific survival and clinical progression-free survival in men with prostate cancer 
treated intermittently with testosterone-inactivating pharmaceuticals. Urology 70 506-510. (doi:10.1016/ j.urology.2007.04.015)

Seidenfeld J, Samson DJ, Hasselblad V, Aronson N, Albertsen PC, Bennett CL \& Wilt TJ 2000 Single-therapy androgen suppression in men with advanced prostate cancer: a systematic review and meta-analysis. Annals of Internal Medicine 132 566-577.

Sharifi R, Bruskewitz RC, Gittleman MC, Graham SD Jr, Hudson PB \& Stein B 1996 Leuprorelin acetate $22.5 \mathrm{mg}$ 12-week depot formulation in the treatment of patients with advanced prostate cancer. Clinical Therapeutics 18 647. (doi:10.1016/S0149-2918(96)80215-3)

Silva ED, Ferreira U, Matheus W, Faria EF, Silva GD \& Saito M 2012 Goserelin versus leuprolide in the chemical castration of patients with prostate cancer. International Urology and Nephrology [in press]. (doi:10.1007/s11255012-0134-z;PMID:22315155)

Smith MR 2007 Obesity and sex steroids during gonadotropinreleasing hormone agonist treatment for prostate cancer. Clinical Cancer Research 13 241. (doi:10.1158/1078-0432. CCR-06-2086)

Smith M \& McGovern F 2001 Gonadotropin releasing hormone agonist failure in a man with prostate cancer. Journal of Urology 166 211. (doi:10.1016/S00225347(05)66115-0)

Suzuki H, Okihara K, Miyake H, Fujisawa M, Miyoshi S, Matsumoto T, Fujii M, Takihana Y, Usui T, Matsuda T et al. 2008 Alternative nonsteroidal antiandrogen therapy for advanced prostate cancer that relapsed after initial maximum androgen blockade. Journal of Urology 180 921-927. (doi:10.1016/j.juro.2008.05.045)

Tanaka N, Fujimoto K, Hirao Y, Shimizu K, Tsujimoto S \& Samma S 2007 Endocrine response to a single injection of goserelin $3.6 \mathrm{mg}$ or leuprolide $3.75 \mathrm{mg}$ in men with prostate cancer. Archives of Andrology 53289. (doi:10.1080/01485010701601222)

Tombal B 2005 Appropriate castration with luteinising hormone releasing hormone (LHRH) agonists: what is the optimal level of testosterone. European Urology Supplements 4(5) 14-19. (doi:10.1016/j.eursup.2005.04.004)

Vogelzang NJ, Chodak GW, Soloway MS, Block NL, Schellhammer PF, Smith JA Jr, Caplan RJ \& Kennealey GT 1995 Goserelin versus orchiectomy in the treatment of advanced prostate cancer: final results of a randomized trial. Zoladex Prostate Study Group. Urology 46 220-226. (doi:10.1016/S0090-4295(99)80197-6)

Wheeler MJ, D’Souza A, Matadeen J \& Croos P 1996 Ciba Corning ACS: 180 testosterone assay evaluated. Clinical Chemistry 421445.

Wilke TJ \& Utley DJ 1987 Total testosterone, free-androgen index, calculated free testosterone, and free testosterone by analog RIA compared in hirsute women and otherwise normal women with altered binding of sex-hormone binding globulin. Clinical Chemistry 331372.

Yri OE, Bjoro T \& Fossa SD 2006 Failure to achieve castration levels in patients using leuprolide acetate in locally advanced prostate cancer. European Urology 49 54. (doi:10.1016/j.eururo.2005.09.009)

Zherdev AV, Byzova NA, Izumrudov VA \& Dzantiev BB 2003 Rapid polyelectrolyte-based immunofiltration technique for testosterone detection in serum samples. Analyst 128 1275. (doi:10.1039/b303288d)

\author{
Received in final form 4 March 2012 \\ Accepted 6 March 2012 \\ Made available online as an Accepted Preprint \\ 6 March 2012
}

